\title{
MORTE RITUAL: REFLEXÕES SOBRE O “SUICÍDIO" SURUWAHA
}

KARINY TEIXEIRA DE SOUZA ${ }^{1}$

UFAM

MÁRCIO MARTINS DOS SANTOS ${ }^{2}$

$M P F$

\begin{abstract}
RESUMO: Este trabalho, ao analisar uma prática sócio-cultural do povo Suruwaha - a "morte ritual" - tem como objetivo problematizar e corroborar com a revisão conceitual do termo "suicídio", considerando-o inapropriado para o que de fato ele representa neste caso específico. A reflexão deste caso, feita a partir de uma revisão de parte da literatura antropológica sobre esse povo, pretende evidenciar os riscos e limitações que podem ser acarretados por este "olhar ocidentalizado" em relação a uma prática indígena. A análise antropológica de questões relacionadas à "morte ritual" dos Suruwaha indubitavelmente nos conduz a interessantes leituras acerca dos resultados e significados do processo de contato da "sociedade ocidental" com os povos indígenas. Ao mesmo tempo, demonstra a complexidade das culturas ditas tradicionais enquanto objetos de estudo, uma vez que estas se mostram passiveis de constantes e complexas transformações e reelaborações.
\end{abstract}

PALAVRAS-CHAVE: práticas culturais; Amazônia; suicídio; morte ritual.

ABSTRACT: This paper, by analyzing a socio-cultural practice of the Suruwaha people - the "ritual death" - aims to question and corroborate with the conceptual review of the term "suicide", considering it inappropriate for what in fact this particular case represents. The reflection on this case, based on a review of the anthropological literature about these people, tries to highlight the risks and limitations that may be generated by this "western look "in relation to an indigenous practice. The anthropological analysis of issues related to the "ritual death" of the Suruwaha undoubtedly leads us to interesting conclusions about the results and meanings of the contact between the "Western society" and indigenous peoples. At the same time, it demonstrates the complexity of the so-called traditional cultures as objects of study, since they are likely to suffer constant and complex transformations and re-elaborations.

KEYWORDS: cultural practices; Amazon; suicide; ritual death.

\footnotetext{
${ }^{1}$ Especialista em Gestão para o Etnodesenvolvimento e Mestranda em Antropologia Social (UFAM). Email: karinyteixeira@yahoo.com.br .

${ }^{2}$ Mestre em Antropologia Social (UFRGS), Analista Pericial em Antropologia do Ministério Público Federal (MPF), atuando na Procuradoria da República no Tocantins. E-mail: marciomsantos@gmail.com.
}

Espaço Ameríndio, Porto Alegre, v. 3, n. 1, p. 10-24, jan./jun. 2009. 
KARINY TEIXEIRA DE SOUZA e MÁRCIO MARTINS DOS SANTOS - Morte ritual...

\section{Introdução}

As reflexões e debates sobre a Amazônia evidenciam não apenas como esta região foi "construída" a partir do imaginário colonizador, mas também o quanto ainda persistem as tentativas de universalização do mesmo.

Em relação à construção do processo imaginário, Laplantine esclarece que "o imaginário não é a negação total do real, mas apóia-se no real para transfigurá-lo e deslocá-lo, criando novas relações no aparente real" (LAPLANTINE e TRINDADE, 2008, s/n). Assim, podemos dizer que os primeiros viajantes, ao adentrarem a Amazônia, evocaram imagens já conhecidas e familiares, modificaram-nas e, através de suas construções mentais, "inventaram" a Amazônia.

Pretendemos, aqui, enfocar como o indígena, ator inseparável da idéia de Amazônia, tornou-se alvo desta invenção, ou seja, como o olhar eurocêntrico construiu a imagem genérica do 'índio', através da transfiguração do real. Para tanto, tomaremos como análise uma prática sócio-cultural que ocorre entre o povo Suruwaha: a "morte voluntária" ou, em outros termos, "morte ritual". Ao usar esta segunda expressão, pretendemos demonstrar como tal prática não ocorre num vazio, sendo parte de um contexto bastante complexo e seguindo uma forma padronizada, com etapas definidas, formas "corretas" de executar os diferentes "atos" e prescrições relativas ao que não deve ser feito.

Ressalte-se que, sob uma ótica "ocidental", tal prática é mais conhecida por "suicídio", estando, portanto, sua imagem habitualmente impregnada pelas nossas concepções acerca do fenômeno. A análise deste caso pretende evidenciar os riscos iminentes deste "olhar ocidentalizado" em relação a uma prática indígena, partindo do que Rodolpho nos diz sobre o fato de "as idéias que temos sobre alguns temas que não são necessariamente corretas - podem, igualmente nos ajudar a pensar sobre o por quê destes sensos comuns perdurarem" (RODOLPHO, 2004, p. 139).

O presente trabalho, além de pretender colaborar com a revisão conceitual do termo "suicídio", considerando-o inapropriado para o que

\footnotetext{
3 "No Brasil sabe-se da ocorrência de casos esparsos em vários grupos indígenas (Paresi, Tikuna, Yanomami), muito embora a questão tenha passado despercebida até a década de 80 , quando se detectou um recrudescimento do suicídio entre os Guarani no Mato Grosso do Sul" (DAL POZ, 2000, p. 98).
} 
KARINY TEIXEIRA DE SOUZA e MÁRCIO MARTINS DOS SANTOS - Morte ritual...

de fato ele representa, no caso específico dos Suruwaha, ainda evidenciará o choque acarretado pelo contato entre povos possuidores de visões de mundo bastante diferentes, bem como o desequilíbrio existente na correlação de forças que permeia esta relação.

\section{O Ser Suruwaha ${ }^{4}$}

O povo Suruwahá foi formado a partir da unificação de diversos subgrupos autônomos que, apesar de serem da mesma etnia, possuíam autodenominações diferentes: Jokihidawa, Tabosorodawa, Adamidawa, Nakydanidawa, Sarakoadawa, Yjanamymady, Zuruahã, Korobidawa, Masanidawa, Ydahidawa, Zamadawa (DAL POZ, 2008). Cada qual habitava seu próprio território, porém falavam a mesma língua e mantinham contato entre si. Essa unificação forçada foi provocada pela onda de invasões decorrentes da atividade extrativista (borracha e sorva) e, conseqüentemente, pelas epidemias e mortes. Não é possível precisar o período histórico exato em que este processo ocorreu, pois a bibliografia aponta referências que vão desde aproximadamente seis ou sete décadas (FRANK e PORTA, 1996b) até cem anos atrás (KROEMER, 1994). Atualmente, estes indígenas habitam uma área de 239.070 hectares, homologada em 1991 e localizada na bacia do Rio Purus, município de Tapauá-AM.

Com uma população estimada em 136 pessoas $^{5}$, o primeiro contato sobre o qual se tem registro foi feito pela pastoral indigenista de Lábrea-AM, vinculada ao Cimi (Conselho Indigenista Missionário) ${ }^{6}$, datando de 8 de maio de 1980 (KROEMER, 1994, p. 11). Posteriormente, já em dezembro de 1983, o povo é contatado "oficialmente" pela Fundação Nacional do Índio (Funai). No ano seguinte, membros da

\footnotetext{
${ }^{4}$ Entre as várias grafias empregadas, optamos pela adotada, atualmente, pelo Conselho Indigenista Missionário, cuja colaboração foi fundamental para realização deste trabalho.

${ }^{5}$ Dado obtido através de entrevista com Jemerson Higino de Azevedo, membro do Cimi (Conselho Indigenista Missionário) que atua junto aos Suruwahá.

${ }^{6} \mathrm{O}$ Cimi é um organismo vinculado à CNBB (Conferência Nacional dos Bispos do Brasil) que apóia as comunidades, povos e organizações indígenas em todo o país, com o objetivo de fortalecer seu processo de autonomia.
} 
KARINY TEIXEIRA DE SOUZA e MÁRCIO MARTINS DOS SANTOS - Morte ritual...

Jocum (Jovens com uma Missão) também passam a ter contato com os Suruwaha?.

Assim, trata-se de um povo de contato recente, possuidor de relações consideravelmente limitadas com a sociedade envolvente. Suas relações mais estreitas se dão, sobretudo, com dois órgãos federais, a Funai e a Funasa (Fundação Nacional de Saúde), com o Cimi e com a Jocum. Entretanto, há de se ressaltar que, se até bem pouco tempo atrás os Suruwaha não saíam da área para a cidade, atualmente há remoções realizadas pela Funasa para tratamento de doenças; estas saídas, no entanto, têm sido estimuladas pela Jocum, que, sob pretextos diversos, como prestar assistência nos campos de saúde e educação, as utiliza para fins proselitistas (as implicações desta atitude, por ter relação com o que se pretende enfocar neste trabalho serão, ainda que de maneira sucinta, abordadas posteriormente).

Não obstante, apesar do pouco contato, o povo Suruwaha tornouse conhecido, até mesmo na mídia, em virtude da prática de "suicídio", ainda pouco compreendida pela sociedade nacional, habituada a interpretações e julgamentos feitos sem a avaliação de que trata-se de um povo que detém concepções culturais diferenciadas das nossas, e cujas formas próprias de organização social, valores e processos históricos definem um "Ser Suruwaha" que é bastante distinto da concepção de pessoa vigente em nossa sociedade. Essa visão holística será necessária para a compreensão antropológica da prática de morte ritual, uma vez que, tal qual Geertz (1989, p. 28), refutamos a concepção "estratigráfica" do homem ${ }^{8}$.

Basicamente, este antropólogo norte-americano pretende dizer que a própria definição de "humano" está diretamente relacionada com uma consideração da diversidade de formas de vivenciar e relacionar-se com o mundo. Nas suas palavras: "o que os homens são, acima de todas as outras coisas, é variado. (...) ser humano não é ser Qualquer Homem; é ser uma espécie particular de homem, e sem dúvida os homens

\footnotetext{
${ }^{7}$ Jovens Com Uma Missão (Jocum) é um movimento internacional de evangélicos. "São objetivos da Missão: Apresentar Jesus Cristo, pessoalmente, a esta geração, mobilizando o maior número possível de pessoas para ajudar nesta tarefa; Treinar e equipar cristãos para o cumprimento da grande Comissão" (JOCUM, 2008).

${ }^{8}$ Segundo esta concepção o homem seria composto por níveis - orgânico, psicológico, social e cultural "cada um deles superposto aos inferiores e reforçando os que estão acima dele. À medida que se analisa o homem, retira-se camada após camada, sendo cada uma dessas camadas completa e irredutível em si mesma (...)" (GEERTZ, 1989, p. 28).
}

Espaço Ameríndio, Porto Alegre, v. 3, n. 1, p. 10-24, jan./jun. 2009. 
KARINY TEIXEIRA DE SOUZA e MÁRCIO MARTINS DOS SANTOS - Morte ritual...

diferem..." (GEERTZ, 1989, p. 64-65). Em suma, "a humanidade é tão variada em sua essência como em sua expressão" (GEERTZ, 1989, p. 49).

Os povos indígenas evocam esta diferença, normalmente explícita em seus mitos de origem, a exemplo do que nos narram os Suruwaha:

Um dia, Aijimarihi, o criador do mundo, pegou frutinhas de karaba e, esfregando-as com as mãos, jogou-as na terra. Nasceu gente, mas o ancestral não gostou, rejeitando-as. São os jara, os brancos.

Numa nova tentativa de criar gente pegou frutinhas de sukuru zibi e, esfregando-as com as mãos, jogou-as na terra. Nasceu mais gente, índios não Suruwahá, e Aijimarihi tornou a rejeitá-la.

$\mathrm{Na}$ terceira tentativa pegou frutinhas de dagam'sakara, a árvore de breu, e esfregando-as com as mãos, jogouas na terra. E dessa vez nasceu gente, os Suruwahá" (KROEMER, 1994, p. 151).

\section{A "morte voluntária" segundo os Suruwaha}

Ao abordar este tema, torna-se fundamental partir de uma visão interna, ou seja, considerar a existência de entendimentos e concepções próprias do povo Suruwaha em relação a conceitos como "vida" e "morte".

Os Suruwaha acreditam na existência de outra vida, após a morte. O caminho ideal de passagem para esta outra vida seria, somente, a ingestão do kunaha, veneno também conhecido como timbó (comumente utilizado em certa técnica de pescaria). "Dizem os índios que a existência humana só tem sentido quando se visa o suicídio. A linha diretriz do entendimento sobre a vida aponta o suicídio como a máxima de todos os valores" (KROEMER, 1994, p. 78).

A "outra vida" seria o melhor lugar para se viver, um lugar de muita alegria, onde se reencontra com os antepassados e onde as pessoas não envelhecem jamais. Todavia, só chegam a este lugar aqueles que morrem pela ingestão do veneno. Quem morre por velhice será privado deste lugar e sua alma ficará vagando sem destino. Assim, as pessoas mais idosas, vítimas de zombaria por parte de crianças e 
KARINY TEIXEIRA DE SOUZA e MÁRCIO MARTINS DOS SANTOS - Morte ritual...

adolescentes por não terem ingerido o timbó, tornam-se caladas e distantes, sabedoras que, ao não seguirem o costume, excluíram-se da possibilidade do reencontro com aqueles que já se foram.

As virtudes morais e físicas, estas acentuadamente presentes na juventude e expressas na força, no vigor, na alegria, na participação nos rituais, são muito estimadas pelos Suruwaha. Para eles, é inconcebível pensar que vão envelhecer e tornar-se dependentes; rejeitam a possibilidade da decadência física, da perda da vitalidade e da independência. Assim, embora o papel dos anciãos seja respeitado, aqueles que passam pelo infortúnio de depender de outrem para comer e/ou para realizar suas atividades mais essenciais, serão, de certa maneira, "desprezados" e "discriminados". Os mais velhos serão chamados de hosa, que significa "não presta, está acabado" (KROEMER, 1994, p. 72).

De acordo com os Suruwaha "não é bom morrer velho, é bom morrer jovem e forte" (DAL POZ, 2008). Por esta razão, as estatísticas indicam que o índice da morte voluntária é maior nesta faixa etária: entre os 15 e 20 anos para as mulheres e entre os 20 e 25 anos entre os homens ${ }^{9}$.

A velhice é tida como a segunda alternativa de vida, como uma alternativa mais penosa ao "verdadeiro caminho", ou seja, à morte por ingestão de kunaha. Nas palavras de Kroemer: "não encontrando mais sentido na existência terrestre, os Zuruahá projetaram sua realização no mundo do além, onde continua sua existência como Kunahã-Made, 'o povo do veneno'" (KROEMER, 1994, p. 129).

\section{Morte ritual: a simbologia de um "drama"}

A morte voluntária entre os Suruwaha é uma prática relativamente recente:

(...) tem suas origens na situação histórica, quando a frente pioneira extrativista avança, exterminado os Zuruahá pela gripe, armas de fogo e epidemias de sarampo. Seus pajés iniciados foram eliminados,

\footnotetext{
${ }^{9}$ As notícias sobre suicídios em populações indígenas no Brasil caracterizam o fenômeno como específico de uma população jovem e adolescente (ERTHAL, 1998).
} 
KARINY TEIXEIRA DE SOUZA e MÁRCIO MARTINS DOS SANTOS - Morte ritual...

reduzindo vários grupos de mesma língua e cultura com autodenominações diferentes, antes espalhados ao longo do rio Cuniuá desde a boca do Riozinho até o Coxodoá. Os poucos sobreviventes se refugiaram no atual território, autodenominando-se, a partir de então, Zuruahá. A nova situação histórica provocou um colapso psicológico entre esse povo, e a falta dos iniciados causou um caos existencial, levando-os a uma reinterpretação de seu mundo religioso, fundamentando, assim, a nova filosofia sobre o sentido de sua existência (KROEMER, 1994, p. 78).

Segundo Dal Poz, tratar-se-ia de um empréstimo cultural oriundo dos Catuquina (2000, p. 117). Contudo, uma vez ressignificada pelos Suruwahá, a prática "passou a fazer parte da identidade do povo" (Jemerson Higino de Azevedo, entrevista, 2008). Desde a tenra idade as crianças são educadas para este ideal de morte, na medida em que presenciam e participam do cotidiano; tanto é assim que a encenação deste ritual é brincadeira costumeira entre elas.

Tomemos, então, o conceito de ritual elaborado por Tambiah:

O ritual é um sistema cultural de comunicação simbólica. Ele é constituído de seqüências ordenadas e padronizadas de palavras e atos, em geral expressos por múltiplos meios. Estas seqüências têm conteúdo e arranjos caracterizados por graus variados de formalidade (convencionalidade), estereotipia (rigidez), condensação (fusão) e redundância (repetição) (TAMBIAH apud RODOLPHO, 2004, p. 141).

Podemos verificar todos estes elementos na prática de morte ritual Suruwaha, embora Peirano (2008) nos alerte quanto aos riscos de uma definição rígida, pois considera que esta precisa ser etnográfica, isto é, aprendida pelo pesquisador em campo, junto ao grupo que ele observa, já que há uma estreita relação entre o ritual e o cotidiano. Isto simplesmente porque, embora os acontecimentos mais fundamentais de uma dada sociedade sejam culturalmente representados, os grupos sociais fazem isso de formas muito distintas (RODOLPHO, 2004).

Identificada como etnotrauma (KROEMER, 1994, p. 11), esta prática ritual passou a mediar as relações e tensões entre o povo, intensificadas em virtude da unificação de diversos subgrupos e do 
KARINY TEIXEIRA DE SOUZA e MÁRCIO MARTINS DOS SANTOS - Morte ritual...

estreitamento das ligações sociais, mas também agiria como "força de autodestruição individual e coletiva" (KROEMER, 1994, p. 78).

Transcreveremos abaixo o ritual em questão, a partir do trabalho de DAL POZ (2000). Faz-se necessário elucidar todos os passos a fim de vislumbrar a integralidade do ritual, já que todas as fases encontram-se relacionadas umas às outras:

1) um determinado acontecimento provoca irritação ou contrariedade;

2) o indivíduo então destrói seus pertences (corta e queima a rede, quebra suas armas e ferramentas, estilhaça os utensílios de cerâmica);

3) os circunstantes, parentes ou não, deixam-no extravasar sua agressividade; procuram disfarçar sua apreensão e, com estudada naturalidade, continuam suas atividades corriqueiras ou começam imediatamente alguma; eles evitam olhar diretamente para o raivoso, mas acompanham furtivamente seus movimentos;

4) se após o acesso catártico a raiva ou o desgosto ainda não o abandonou, o indivíduo emitirá um grito ou logo sairá ostensivamente da casa, correndo em direção a alguma roça para arrancar raízes de timbó;

5) os que acompanhavam discretamente o que se passava avisam os demais (parentes, talvez), e algumas pessoas (geralmente do mesmo sexo) perseguem o suicida ou, se este já está distante, procuram-no nos caminhos que vão dar às roças;

6) se os perseguidores o encontram, tentam tirar-lhe as raízes; caso contrário, o suicida se dirige a um córrego e ali espreme e mastiga o timbó, de modo a ingerir seu sumo; em seguida, bebe um pouco de água para ativar seus efeitos tóxicos;

7) daí, ele volta correndo rumo à casa (alguns não o conseguem, e desfalecem ou morrem no caminho);

8) ali chegando, o suicida é atendido por seus parentes ou outros, o que varia segundo os motivos $e$ as relações que suscitaram a tentativa; a operação de salvamento consiste em provocar o vômito, irritando o esôfago com talos de folhas de abacaxi, esquentar o corpo com abanos aquecidos (tarefa realizada pelas mulheres), bater nos membros dormentes e gritar ao ouvido para despertá-lo, mantendo-o sempre sentado;

9) no curso do tratamento, em geral, as pessoas mostram-se zangadas com 0 suicida, falam-lhe agressivamente e xingam-no; 
KARINY TEIXEIRA DE SOUZA e MÁRCIO MARTINS DOS SANTOS - Morte ritual...

10) a eventual morte do suicida, todavia, espraia uma forte comoção e ganha expressão ritual através de chorosas melopéias; o desfecho dramático motiva outras tantas pessoas (consangüíneos, afins, amigos) a realizar, logo em seguida ou passado algumas horas ou dias, novas tentativas de suicídio, as quais dão início a um novo ciclo de perseguições e medidas de salvamento (DAL POZ, 2000, p. 103).

Kroemer enfatiza a "reação em cadeia" ou "epidemia" advinda da morte ritual que é, ao mesmo tempo, uma etapa do próprio ritual:

(...) a morte de uma menina, mordida de cobra, originava o suicídio do pai, do filho da irmã e do filho do irmão do pai. Meses depois veio outra onda de mortes, ainda em conseqüência das anteriores: uma briga banal entre crianças da viúva de um rapaz que tinha falecido no suicídio anterior e outras iniciou uma reação em cadeia. A viúva se matou, deixando pra trás duas crianças órfãs. Em seguida, a irmã da viúva, que também tinha perdido o marido com um filho pequeno, tomou veneno e morreu. Logo outra irmã correu e se suicidou. Alguns dias depois, numa briga de um jovem casal, o marido acertou, sem querer, um pedaço de madeira na cabeça da esposa que, furiosa, se matou, provocando uma nova onda de suicídios (KROEMER, 1994, p. 79-80).

Várias tentativas podem ser feitas por uma mesma pessoa, antes que a morte, de fato, ocorra. Muitas vezes, os indígenas insinuam que pretendem ingerir o veneno, ou mesmo o tomam em uma pequena quantidade, apenas para manifestar sua raiva ou por conseqüência de uma morte anterior.

Cabe observar ainda que o ritual evidencia o prestígio social de quem o pratica, uma vez que, possuidor das estimadas virtudes físicas e morais, mobilizará um maior número de pessoas para a tentativa de salvamento, ou mesmo para seguir-lhe o gesto. Por outro lado, quando uma pessoa mais velha ameaça tomar o veneno não há comoção para impedi-la; chegam a dizer "deixa tomar, deixa morrer"10.

\section{Durkheim e o suicídio}

\footnotetext{
${ }^{10}$ Relato de Adriana Maria Huber de Azevedo, membro do Cimi que atua junto aos Suruwaha.
} 
KARINY TEIXEIRA DE SOUZA e MÁRCIO MARTINS DOS SANTOS - Morte ritual...

O sociólogo francês Émile Durkheim nos trouxe importantes contribuições em seu clássico estudo sobre suicídio. Comecemos pela sua definição do ato em questão, sem desconsiderar os cuidados necessários quanto aos riscos de cristalização dos conceitos:

Chama-se suicídio todo caso de morte que resulta direta ou indiretamente de um ato positivo ou negativo praticado pela própria vítima, ato que a vítima sabia produzir este resultado. A tentativa de suicídio é o ato assim definido, mas interrompido antes que a morte daí tenha resultado (DURKHEIM, 1983, p. 167).

Apesar de muitos creditarem um viés individual e psicologizante ao suicídio, Durkheim (1983), com sua abordagem sociológica pioneira, buscou demonstrar que tal ato teria um fundamento social e não individual, ou seja, seria resultado de pressões exercidas pela sociedade em relação ao indivíduo. Ele ainda vai além e diz que "cada sociedade tem em cada momento da sua história, uma aptidão definida para o suicídio" (DURKHEIM, 1983, p. 169). Para que essa "aptidão" se manifeste ou não, seria necessário observar alguns fatores:

(...) primeiro, a natureza dos indivíduos que compõem a sociedade; segundo, a maneira como estão associados, ou seja, a natureza da organização social; terceiro, os acontecimentos passageiros que perturbam o funcionamento da vida coletiva, sem alterar no entanto a constituição anatômica desta, tais como as crises nacionais, econômicas etc. (DURKHEIM, 1983, p. 199).

Podemos, então, apontar uma relação entre o que nos diz Durkheim sobre o suicídio e a prática de morte ritual do povo Suruwaha?

Certamente seu enfoque sociológico contribui para a elucidação do fenômeno, pois colabora num direcionamento de nosso olhar para fatos e eventos que dizem respeito a uma coletividade, e não necessariamente às aflições de um indivíduo "autônomo" e "isolado". Todavia, é necessário um esforço para não tentar transpor mecanicamente a análise, pois, ao se tratar de povos indígenas, é fundamental considerarmos as cosmovisões específicas e concepções acerca do que é o indivíduo (se este conceito efetivamente "existir", no 
KARINY TEIXEIRA DE SOUZA e MÁRCIO MARTINS DOS SANTOS - Morte ritual...

grupo investigado) e sua relação com a sociedade. Tudo isso, certamente, acarreta significados próprios acerca da "morte voluntária".

\section{A possibilidade de novas leituras e reelaborações}

A análise antropológica de questões relacionadas ao "suicídio" ou "morte ritual" dos Suruwaha indubitavelmente nos conduz a interessantes leituras acerca dos resultados e significados do processo de contato da "sociedade ocidental" com os povos indígenas, ao mesmo tempo em que demonstra a complexidade da cultura enquanto objeto de estudos, passível de constantes transformações e reelaborações. Neste sentido, comenta Kroemer:

As mortes por epidemias e armas de fogo, o extermínio de todos os líderes espirituais e o sentimento de total abandono levaram os Zuruahá ao desespero. Dawari, um sobrevivente dos Adamidawa, recorreu ao suicídio, bebendo o veneno kunahã. Foi o estopim para outros suicídios, que logo se tornaram uma prática cultural. A partir da morte de Dawari, a história do povo Zuruahá começou a mudar (KROEMER, 1994, p. 129).

Apesar de, como vimos, a morte ritual Suruwaha ser uma prática que foi elaborada a partir de um violento processo histórico, no momento em que ela é dotada de significados pelos indígenas, não deixa de adquirir um caráter de tradicionalidade. Neste contexto, é possível considerar que novas leituras ainda possam ser feitas, culminando em outras ressignificações, ou, até mesmo, no fim desta prática.

Tal hipótese também pode ser corroborada pelo fato de alguns autores destacarem contradições e ambigüidades nesse costume. Kroemer aponta dois aspectos fundamentais: as tentativas de salvamento, por um lado, já que

(...) lutam desesperadamente contra a morte provocada pelo suicídio. Reconhecem a máxima de todos os valores como elemento destrutivo da vida. Há contradição entre as práticas oriundas de padrões culturais que determinam a autodestruição concebida 
KARINY TEIXEIRA DE SOUZA e MÁRCIO MARTINS DOS SANTOS - Morte ritual...

numa ideologia única sobre a existência humana e instruída no processo educativo de socialização, e as práticas de salvamento que indicam uma força étnicosocial, responsável pela sobrevivência do povo (KROEMER, 1994, p. 80).

Por outro, a possibilidade de se poder morrer por velhice:

(...) a morte por velhice, embora tolerada como caminho alternativo, se tornou a opção daqueles que, apesar de várias tentativas de suicídio, sobreviveram. Em outras palavras, a dinâmica da estrutura social criou mecanismos que funcionam como uma espécie de agente de controle para evitar sua autodestruição física e cultural (KROEMER, 1994, p. 129-130).

Em entrevista, a equipe indigenista do Cimi que atua junto aos Suruwaha esclareceu que, apesar da morte ritual, através da ingestão de timbó, ser o caminho ideal de passagem para a outra vida, segundo a concepção do próprio povo, paira uma grande comoção e tristeza quando a comunidade é acometida por um número acentuado de mortes de uma única vez. Nestas ocasiões proferem exclamações como "Suruwaha acabou porque Suruwaha gosta do veneno", que se confronta com "minha saudade nunca passa", saudade referente aos antepassados que estão "na outra vida" e com os quais se encontrarão após a morte ritual. Haveria aí uma tensão entre o "dever cultural" e o sentimento afetivo/social: "Os Suruwaha tem a capacidade de avaliar as diferenças; quando eles vão à cidade percebem e falam que lá há muitos velhos, que há alegria e que a população é bem maior" (Entrevista com Adriana Maria Huber de Azevedo, membro do Cimi, realizada em 23/02 /2008).

\section{Considerações finais}

Se, no encontro com o diferente, com o Outro, cronistas e viajantes, ao descreverem suas impressões sobre a Amazônia, atribuíram aos indígenas características não necessariamente humanas, mas sim antropomórficas, os descrevendo como seres fantásticos e monstruosos, aberrações a habitarem um lugar inóspito, atualmente essa inferiorização continua sendo feita. Não mais através de atributos 
KARINY TEIXEIRA DE SOUZA e MÁRCIO MARTINS DOS SANTOS - Morte ritual...

físicos, mas sim, através da condenação de seus costumes, crenças e tradições.

Suas práticas culturais, como, por exemplo, a morte ritual aqui abordada, incompreendidas pelas concepções "ocidentais" e, num certo sentido, cristãs, vigentes em nossa sociedade, alimentam nosso imaginário e assim julgamos ver, bem diante de nós, seres desprovidos de humanidade e sentido. Trata-se, sem dúvida, de uma interpretação deveras simplista de cosmovisões sofisticadas. Tal mentalidade vem sendo usada por igrejas proselitistas para justificar a conversão desses povos, que acaba tornando-se uma nova prática de dominação, uma nova missão civilizatória. É desta forma que, alegando que seus costumes tradicionais seriam "pecado" e, portanto, "errados", que a Jocum, por exemplo, vem agindo entre os Suruwaha. Portanto, cabe aqui explicitar as conseqüências deste tipo de atuação que, ignorando a diversidade sócio-cultural e, sobretudo, o direito à manutenção desta diversidade, visa transformar o "Outro" num "Igual".

Tomemos a direção apontada por Geertz para entendermos que a cultura deve ser vista "como um conjunto de mecanismos de controle planos, receitas, regras, instruções - para governar o comportamento" (GEERTZ, 1989, p. 56); somemos o redimensionamento dado por Durkheim ao suicídio: "A causa produtora do fenômeno escapa necessariamente a quem só observa os indivíduos; porque ela é exterior aos indivíduos. Para a descobrir é necessário ir além dos suicídios particulares e aperceber o que determina a unidade destes" (DURKHEIM, 1983, p. 201); acrescentemos, por fim o alerta de Rodolpho quanto às singularidades rituais: "o importante na análise dos rituais é não nos deixarmos levar unicamente por nossos valores de racionalidade ou pelos critérios de nossa sociedade, já que estes não são necessariamente válidos para outros grupos" (RODOLPHO, 2004, p. 140): teremos, então, importantes instrumentais a orientar a reflexão sobre a morte ritual Suruwaha, sem incorrer no risco de naturalizar o fenômeno, mas sim tentando encará-lo com um olhar de quem pretende "vê-lo de dentro".

Para Lévi-Strauss (apud RODOLPHO, 2004, p. 145) o ritual seria como um "modelo pelo qual as coisas são ditas", estando relacionado ao viver, à identidade, à continuidade; portanto, também atualiza 
cosmologias e é por elas orientado (PEIRANO, 2000, p. 13). Então, o que os Surwaha querem nos dizer através de sua morte ritual, senão que estão elaborando respostas próprias de resistência e afirmação cultural (por mais contraditório que isso possa parecer) frente ao seu violento processo histórico de contato?

\section{Referências bibliográficas}

DAL POZ, João. Crônica de uma morte anunciada: do suicídio entre os Sorowaha. Revista de Antropologia, São Paulo, v. 43, n 1, p. 89-144, 2000.

Zuruahã. Disponível em: http://www.socioambiental.org/pib/epi/zuruaha . Acesso em: 04 de mar. 2008.

DURKHEIM, Émile. Da divisão do trabalho social; As regras do método sociológico; O suicídio; As formas elementares da vida religiosa. São Paulo: Abril Cultural, 1983. (Os Pensadores).

ERTHAL, Regina Maria de Carvalho. O suicídio Ticuna na região do Alto Solimões AM. 1998. 279 f. Tese (Doutorado em Saúde Pública) - Escola Nacional de Saúde Pública, Fundação Oswaldo Cruz, [1998]. Disponível em: http://portalteses.icict.fiocruz.br/pdf/FIOCRUZ/1998/erthalrmcd/capa.pdf . Acesso em: 07 de jun. 2009.

FANK, Jonia Teresinha; PORTA, Edinéia Lacir. A vida social e econômica dos Sorowaha. Cuiabá: OPAN/CIMI, 1996a.

Mitos e histórias dos Sorowaha. Cuiabá: OPAN/CIMI, 1996b.

. Vocabulário da língua Sorowaha. Cuiabá: OPAN/CIMI, 1996c.

FOUCAULT, Michel. As palavras e as coisas. São Paulo: Martins Fontes, 1995.

GEERTZ, Clifford. A interpretação das culturas. Rio de Janeiro: LTC, 1989.

GONDIM, Neide. A invenção da Amazônia. São Paulo: Marco Zero, 1994.

JOCUM - Jovens Com Uma Missão. Nossa Visão. Disponível em: http://www.jocum.org.br/jocum.php?pagina=nossavisao\&assunto=indice . Acesso em: 10 de mar. 2008.

KROEMER, Gunther. Cuxiuara: o Purus dos indígenas. São Paulo: Loyola, 1985. 
KARINY TEIXEIRA DE SOUZA e MÁRCIO MARTINS DOS SANTOS - Morte ritual...

. A caminho das malocas Zuruahá. São Paulo: Loyola, 1989.

. Kunahã Made, o povo do veneno: sociedade e cultura do Povo Zuruahá. Belém: Mensageiro, 1994.

LAPLANTINE, François; TRINDADE, Liana. O que é imaginário. Disponível em: http://www.portaldetonando.com.br . Acesso em: 04 de mar. 2008.

OLIVEIRA, Cleane S.; LOTUFO NETO, Francisco. Suicídio entre povos indígenas: um panorama estatístico brasileiro. Revista Psiquiatria Clínica, São Paulo, v. 30, n. 1, p. 4-10, 2003. Disponível em: http://www.hcnet.usp.br/ipq/revista/vol30/n1/pdf/4.pdf . Acesso em: 07 de jun. 2009.

PEIRANO, Mariza G. S. A análise antropológica de rituais. Brasília: UnB, 2000. (Série Antropologia, 270). Disponível em: http://www.unb.br/ics/dan/Serie270empdf.pdf . Acesso em: 04 de mar. 2008.

RODOLPHO, Adriane Luisa. Rituais, ritos de passagem e de iniciação: uma revisão da bibliografia antropológica. Estudos Teológicos, São Leopoldo, v. 44, n. 2, p. 138-146, 2004. Disponível em: http://pjp.raposo.googlepages.com/AdrianeLuisaRodolphorituaisrevisobi.pdf . Acesso em: 07 de jun. 2009. 